\title{
Cultura Cultura
}

Revista de Historia e Teria das ldeaias $\quad$ Revista de História e Teoria das Ideias

Vol. 31 | 2013

A Retomada na Filosofia de Eric Weil

\section{Retomar}

uma condição narratológica de textualidades comuns

Reprendre: une condition narratologique de textualités communes

Luís Manuel A. V. Bernardo

\section{(2) OpenEdition}

Journals

Edição electrónica

URL: http://journals.openedition.org/cultura/1904

DOI: $10.4000 /$ cultura.1904

ISSN: 2183-2021

Editora

Centro de História da Cultura

Edição impressa

Data de publição: 1 Dezembro 2013

Paginação: 301-317

ISSN: 0870-4546

Refêrencia eletrónica

Luís Manuel A. V. Bernardo, « Retomar », Cultura [Online], Vol. 31 | 2013, posto online no dia 18 dezembro 2014, consultado a 19 abril 2019. URL : http://journals.openedition.org/cultura/1904 ; DOI : 10.4000/cultura. 1904

Este documento foi criado de forma automática no dia 19 Abril 2019.

(c) CHAM - Centro de Humanidades / Centre for the Humanities 


\section{Retomar}

uma condição narratológica de textualidades comuns

Reprendre: une condition narratologique de textualités communes

Luís Manuel A. V. Bernardo

1 O que é posto em comum depende, em grande parte, de processos textuais específicos que funcionam como condições de possibilidade da partilha dos sentidos que circulam pelo meio da linguagem. Tal implica, por um lado, que o simples uso corrente da linguagem, ainda que indispensável, não seja suficiente para gerar essa comunidade, pois que nem todos os dispositivos linguísticos estão vocacionados para favorecer a convergência, e, por outro, que a comunicação requeira, para o efeito, um trabalho de textualização, directamente orientado para garantir a compreensão do que está em causa. Pretendemos, assim, reflectir sobre uma dessas condições, a de que uma nova enunciação, para se tornar comum, tenha sempre de ser enunciada numa versão enunciativa, já consolidada, não apenas formalmente, mas, também, no que respeita a sequências textuais específicas, estendendo o conceito de retomada que, na filosofia de Eric Weil, surge no âmbito da Lógica da Filosofia, à totalidade da comunicação com pretensão a fazer sentido. Trata-se, portanto, de pensar com Weil, para lá de Weil, num exercício de (in)fidelidade e distanciação que constitui, em si mesmo, uma forma de retomada. ${ }^{1}$

2 A viabilidade de um tal alargamento, em contraponto à concentração nas funções que detém no sistema, encontra-se antecipada pelo filósofo quando escrevia que «é ele [o conceito de retomada] que permite a aplicação da lógica à realidade histórica, em outras palavras, que permite a compreensão dos discursos concretamente sustentados pelos homens do passado e do presente», ${ }^{2}$ que não apenas, como se deduz, dos praticantes da filosofia. Assim, ao longo deste ensaio, procuraremos estabelecer o gesto discursivo de retomar como condição de possibilidade performativa tanto da consolidação, quanto da produção de novos sentidos em enunciados que visem a participação no espaço público e a sua eventual transformação. Com efeito, o que cabe entender por comum não é só o que se partilha, ou se tem por susceptível de se partilhar, o que, assim, está no meio, aspecto tradicionalmente valorizado pela hermenêutica filosófica, mas, também, o que se põe em comum, se antecipa e, sobretudo, se cria como novos processos de comunidade. Ora, este trabalho de criação passa, inevitavelmente, pela definição de horizontes de significação e 
de sentido e, logo, depende, antes de mais, da sua ocorrência na linguagem, pela linguagem e em termos linguísticos. Esta é o prévio de qualquer interacção comunitária, o seu médium, mas não menos o seu espaço de retroacção e de reflexão. Cabe, então, conceber a retomada, antes de mais, no âmbito da linguagem, como um dispositivo intralinguístico destinado a possibilitar a produção de sequências articuladas, tendencialmente sensatas e, por isso, partilháveis por universos cada vez mais vastos.

3 A este propósito, impõe-se ter em conta a sugestão de Weil de que a retomada é a condição de possibilidade da criação da "primeira linguagem», ${ }^{3}$ na medida em que «tão logo exista a retomada, existe linguagem». ${ }^{4}$ Como ele tem o cuidado de frisar, não se trata de uma precedência cronológica, mas de uma anterioridade lógica, que deve ser entendida, quanto a nós, de três modos complementares. Primeiro, numa acepção mais geral, que todo e qualquer acto linguístico já pressupõe essa dobra que consiste em retomar, e este será, decerto, um dos significados da frase mais enigmática, segundo Gilbert Kirscher, da Lógica da Filosofia, escrita já no final da categoria formal do sentido: «o início está na retomada». ${ }^{5}$ Segundo, numa perspectiva mais restrita, que esse dispositivo permite a emergência de uma primeira linguagem, ou seja, de um primeiro universo de significação comum, constituído por uma narrativa particular que pode, por sua vez, ser retomada em narrativas e discursos sucessivos, eventualmente, mais complexos, em virtude da multiplicação de processos de retoma. Terceiro, do ponto de vista de uma compreensão dialéctica, uma vez que a retomada supõe uma configuração de carácter discursivo, mesmo que incipiente, é o discurso que revela a omnipresença da linguagem e não o inverso. Consequentemente, se esta omnipresença genética é decisiva para a universalidade do retomar, em acção em todos os domínios da expressão e da comunicação, importa entender que o tipo que lhe corresponde, idêntico ao de todo o uso da linguagem para efeitos de criação de textualidades comuns, é o da dupla reflexão, de tal modo que se deverá supor que qualquer utilização da linguagem se encontra sob o signo da retomada na medida em que a linguagem encerra a potencialidade de gerar, por essa via, narrativas de vária ordem, aptas a compreender, a traduzir, senão mesmo a inventar o(s) sentido(s) do existir em comum, cuja consistência se oferece afim daquela padronizada pela função discursiva.

4 Assim sendo, há que insistir na distinção entre a potencialidade de gerar consensos inerente aos processos linguísticos, na medida em que estes carregam uma funcionalidade reflexiva incipiente, e a pretensão mais orientada, ainda que fundada por aquela e naquela, de chegar a um nível de comunicação em que todos os intervenientes estejam simultaneamente de acordo sobre o que é posto em comum, bem como sobre a intenção de fazer valer essa gestualidade. Aplica-se aqui a distinção weiliana entre linguagem e discurso, a primeira marcada pela espontaneidade expressiva, o segundo pela escolha deliberada da coerência e da razoabilidade, conferindo aos dois termos, igualmente, a maior amplitude. Todavia, entre os dois níveis, por mais afastados que possam aparecer em determinados momentos, a retomada surge como um princípio performativo de continuidade, não tanto por alinhar construtivamente elementos simples de modo a produzir outros mais complexos, ou por garantir a permanência dos processos linguísticos de base nas formações mais artificiais, quanto por, regressivamente, revalidar a espontaneidade primeira a partir da estruturação intencionada correspondente à textualização discursiva.

Deste modo, se mesmo o que Weil designa como a "poesia fundamental», caracterizada como espontaneidade, criatividade e revelação, ${ }^{6}$ está na dependência do retomar, tendo 
em conta a diferença de intencionalidades entre essa linguagem primordial e os discursos que dela se vão destacando, em virtude de um intuito compreensivo e transformador, impõe-se considerar uma distinção significativa entre a evidência primeira dessa comunidade linguística, com toda a força de um tipo de presença incontestada porque incontestável, na qual a retomada se efectua directamente enquanto condição transcendental da linguagem, e a possibilidade de reconstituição de formas de presença discursivas graças à tomada de consciência seja do valor dos segmentos textuais retomados, seja do peso dos discursos disponíveis para retomar na produção de uma discursividade comum, seja, sobretudo, da universalidade dessa condição que faz de todos os discursos «retomadas da categoria do sentido» ${ }^{7}$ e da filosofia "a ciência do sentido». ${ }^{8}$ Uma vez que o que pode tornar-se comum, porque deve sê-lo, para aqueles que procuram essa consensualidade, assenta na conviç̧ão de que «o sentido da existência é ter um sentido", ${ }^{9}$ a figura textual mais complexa do discurso corresponde, assim o cremos, ao verdadeiro modelo narratológico dessas textualidades que visam favorecer a partilha dos sentidos enunciados, em detrimento daquele, atomista, largamente difundido, que reconduz o processo da comunicação ao tipo simplificado da pergunta orientada para uma resposta em termos de «sim» ou de «não».

6 Retomar decorre, por conseguinte, antes de mais, e ao contrário do que se costuma considerar, da inventividade inerente à linguagem, que perpassa, igualmente, o discurso, que este reconfigura de acordo com princípios de intencionalidade e de coerência que lhe são próprios: o que há de repetitivo, de esquemático, de mecânico no gesto de retomar é, assim, a consequência da dinâmica da inventividade que faz depender a construção de textualidades significativas da mimese parcial de textualidades disponíveis. Com efeito, estamos perante uma condição narratológica, na medida em que, em consequência do desdobramento pressuposto pela reflexividade, envolve sempre a estruturação de segmentos de carácter textual, ficcionais e não-ficcionais, por mais básicos que se ofereçam. Neste sentido, retomar é o que permite a invenção do sentido da e na linguagem, depois de ter sido compreendido como condição transcendental da produção do sentido no discurso. Por conseguinte, sendo claro que a linguagem é o mais comum, em extensão, só pelas retomadas é que, nessa imensidade relativamente indefinida de enunciações possíveis, se demarcam aquelas aptas a tornarem-se comuns, compreensivamente, ou seja, a figurarem como estâncias narratológicas que, por sua vez, podem ser reconhecidas pelos falantes como merecedoras de retoma.

7 Não será decerto alheio a esse facto a existência de uma espécie de incremento do recurso ao retomar nos discursos que mais apostam nos efeitos transformadores de enunciações destinadas a conciliar o sentido discursivo e o existencial, como é o caso daqueles que estão centrados na Acção, relativamente à qual, como Weil salienta, «as retomadas são (...) particularmente numerosas e complicadas». ${ }^{10} \mathrm{O}$ aparente paradoxo desta consideração desfaz-se se se tiver presente a relação que estabelecemos entre retomada e invenção, que afasta a confusão corrente entre retomar e repetir: é que, se o segundo gesto supõe a colagem ao modelo, o primeiro diz respeito ao recurso necessário a uma matriz para viabilizar a proposta de um sentido parcialmente inovador. Assim, dever-se-á pensar na possibilidade de a exponenciação do retomar, que importa não confundir com o aumento de retomadas do mesmo teor, ser, eventualmente, um sinal de uma utilização pragmática do retomar que visa potenciar a eficácia das textualidades complexas, como são os discursos, para gerarem figuras do comum. Esta hipótese está directamente correlacionada com o facto de a retomada, para além de constituir um processo intra- 
linguístico e de corresponder a uma função intertextual, estar, ainda, em acção na dimensão discursiva, entendida em sentido estrito, como utilização deliberada de constructos textuais orientados especificamente para a instituição de sentidos tendentes a configurarem visões do mundo.

Sendo óbvio que todo o pôr em comum, por ser narratológico, não é menos histórico, e vice-versa, urge ponderar a existência de uma zona de interferência entre narratividade e historicidade, na qual se manifeste a forma como a inventividade concreta se encontra condicionada por uma certa lógica textual, que delimita a variedade de narrativas e antecipa o horizonte de sentidos que podem fazer sentido nessa configuração, do mesmo modo como a existência de múltiplas narrativas, susceptíveis de remissão a uma mesma matriz, exibe o carácter generativo dessas textualidades estruturadoras. Ora, o que a Lógica da Filosofia patenteia é a existência de um conjunto de discursos matriciais, cujo núcleo generativo pode ser identificado, e que formam um património discursivo comum, disponível para ser retomado pelos discursos efectivamente tidos em contextos históricos particulares. Por sua vez, ainda que circunscrito ao campo do pensamento filosófico, Weil mostra como as concepções particulares que constituem o objecto privilegiado da historiografia resultam em retomadas, porquanto em diferentes momentos e em diferentes circunstâncias, a pluralidade de sentidos possíveis, possibilitada pela linguagem, se vê orientada para e por um desses discursos padrão, que, dessa feita, vê confirmado o seu alcance poético.

9 Na medida em que se torna manifesto, por uma tal articulação entre estrutura e evento, que esses discursos estruturadores funcionam tanto como limites de discursividade, quanto como horizontes de significação, quanto, ainda, como geradores de discursos concretos diversificados, a viabilidade desta zona quasi-ideal, quasi-real, intermédia entre a generalidade da linguagem e a particularidade de um discurso efectivo, aparece-nos como decisiva para a eficácia do que seríamos tentados a designar como a dupla retomada, aquela que os segmentos discursivos, retomados de discursos concretos, autoral e/ou historicamente identificáveis, sofrem estando suportada pela escolha primeira de retomar um desses discursos modelares como critério da sensatez das retomadas. Cada uma destas configurações discursivas-generativas prototípicas corresponde, assim, ao que Eric Weil compreende como uma categoria, tal como nós a interpretamos. ${ }^{11}$ No que respeita ao nosso problema, um dos interesses desta concepção advém precisamente do modo como supõe essa duplicação lógica, quer pelo facto de contemplar um nível propriamente discursivo de retomada, com os seus processos próprios, diferenciados dos da linguagem em geral, mas não fora do seu âmbito, quer por essa proposta se encontrar concretizada pela exposição de cada um desses discursos originários, bem como do sentido de algumas das respectivas retomadas ao longo da história do pensamento filosófico.

0 estatuto da categoria afigura-se aqui diferente daquele que detém na filosofia de Kant ou na de Aristóteles, como o próprio Weil assinala, precisamente por ser lógico-discursivo e não metafísico, prévio, portanto, ao conhecimento do mundo, em sentido estrito, pois que o que cabe entender quer por conhecimento, quer por mundo a ser conhecido, depende do quadro compreensivo determinado por esse discurso-base que traceja as linhas de significação e circunscreve os limites do que pode fazer sentido. Deste modo, a existência desses discursos-tipo, situando-se para cá da oposição sujeito-objecto, secundariza o problema complexo da heterogeneidade relativa dos dois termos da relação, pela interposição de um terceiro termo, igualmente, esquemático, mas 
beneficiando da sua pertença ao meio linguístico. O esquematismo, neste caso, não pressupõe uma faculdade própria, como a imaginação, ou um objecto específico, como a imagem, ${ }^{12}$ mas está dado na própria discursividade, simultaneamente, como discurso-tipo e tipo de discurso. É que, por exemplo, um qualquer enunciado, em torno da categoria da Consciência ou da Acção, não tem o mesmo teor, substantivo, lexical, sintáctico, pragmático ou argumentativo, pois que cada uma configura um tipo de enunciação textual característica, que nos permite remeter o sentido desse enunciado para essa esfera de enunciação, o que, sem prejuízo dos recortes e das combinações respectivos, deverá afectar as correspondentes retomadas: não se discorre sobre, com vista a, ou a partir do discurso categorial da Acção ou da Consciência com as mesmas estratégias textuais, nem com os mesmos horizontes de significação.

Esta associação numa mesma esfera dos processos que, no criticismo kantiano, apareciam como particulares de cada função da razão, teórica, prática, judiciária - esquema, tipo, símbolo -, evidencia, por conseguinte, que o que está em causa é a concepção de uma zona de discursividade, enunciativa, pragmática e hermenêutica, logicamente, anterior, mas, na realidade, entrosada nas enunciações, com pretensão à sensatez, que condiciona $\mathrm{e}$ possibilita, incluindo, portanto, aquelas, segundas, judicativas, de cariz gnosiológico, prático, estético ou teleológico. Desta feita, o discurso categorial fornece um esquema formal de enunciação, mas de uma formalidade de segundo grau, diríamos, diversa, portanto da pura formalidade que Kant atribuí às categorias, orientada para mediar efectivamente a expressão linguística e condição desejada de que esta se submeta à lógica do sentido, porquanto já introduz uma textualidade mínima tipificada, com a sua dialéctica narratológica, destinada a ser retomada, que não propriamente aplicada. Claro que, para cada discurso concreto, que retoma um desses esquemas narratológicos, há sempre um conjunto de condicionantes metafísicos próprios, que requerem processos considerados, convencionalmente, de adequação, aplicação, subsunção ou síntese, como aqueles a que se refere a crítica do conhecimento proposta por Kant, mas, para que essas perspectivas façam sentido, têm inevitavelmente de retomar uma dessas narratividades paradigmáticas.

o problema lógico fundamental não é, assim, o das condições de possibilidade do conhecimento objectivo, mas o das condições dessas condições, ou seja, o das condições de possibilidade de uma enunciação sensata, que, enquanto tal, se estabeleça como uma enunciação potencialmente comum, logo, pronta a retomar. Consequentemente, quanto melhor se compreender o dinamismo que assiste ao jogo entre essas tramas basilares e as retomadas que induzem, tanto melhor se conseguirá orientar os discursos concretos para a invenção de sentidos congregadores, com os quais os sujeitos possam identificar-se, retomando-os, por sua vez, naquele que designámos como o segundo processo de retomada. Só que, por sua vez, paradoxalmente (?), essa compreensão depende de um processo próprio de retomar as retomadas, que cabe designar como lógico, interrogandoas sobre o sentido dos sentidos que procuram fazer valer, de modo a destacar a textualidade discursivo-narratológica que lhes serve de discursividade comum e de princípio generativo, uma vez que essa zona arquetípica, precisamente, porque lógica, que não ôntica ou metafísica, ${ }^{13}$ vem dada na própria inventividade do enunciar.

Retomar é, por conseguinte, igualmente, a condição de possibilidade de uma filosofia que aspira a constituir-se como uma lógica da filosofia, circularidade que não deve surpreender, se se atentar em que essa intenção só pode concretizar-se discursivamente. A uma das dificuldades maiores dos estudos weilianos, a de saber qual o estatuto do modo 
de aceder a esses discursos categoriais, julgamos ser adequado responder que se trata de um tipo particular de retomada que consiste em sujeitar os discursos à pergunta sobre o sentido do sentido. $O$ que a diferencia é que a retomada lógica configura uma «reflexão dupla» ${ }^{14}$ como consciência de si e como retomada de outros discursos cuja congruência se intenta reconstruir. Esta centralidade do retomar impede que a análise compreensiva que a lógica leva a cabo se confunda com uma fenomenologia do espírito, pois que a processologia que põe a descoberto nem preexiste ao gesto desse retomar, nem é de outro teor que o da própria discursividade, aproximando-a antes de um exercício de cariz hermenêutico, dedicado a relevar os efeitos da categoria formal do sentido nos enunciados substantivos, com o qual, contudo, também, não coincide rigorosamente, em virtude quer da expectativa de vir a fixar configurações discursivas, relativamente estabilizadas face às divergências dos discursos históricos, quer do carácter transcendental que lhes atribui. Assim, esse esforço, por actuar numa zona híbrida, quanto a nós, realmente dialéctica, suscitando um movimento constante entre a busca de uma certa unificação, permitida pela coerência narratológica dos enunciados, e a interpretação da diversidade de enunciações, cuja pulverização, por ser compreendida, não resulta anulada, não deverá ser julgada improcedente, na exacta medida em que torna patente, tanto pela regressão analítica, quanto pela inventividade construtiva, a presença desse lastro discursivo intermédio como condição de possibilidade do retomar e das respectivas retomadas como condições de operacionalidade dessa coerência narratológica. Ora, uma vez identificado esse estrato, mormente por ter sido retomado processualmente, impõe-se integrá-lo no conjunto de condições narratológicas, em geral, e daquelas da qual dependem as textualidades que visam explicitamente a produção de enunciados comuns, em particular.

A universalidade do gesto de retomar no domínio das textualidades que aspiram a fazer sentido - seria de ponderar se só nessa esfera - a não confundir com uma suposta exclusividade, enraíza-se, precisamente, nesta articulação reflexiva entre a sua função analítica e a sua função construtiva, a qual instaura, no interior da própria discursividade, para cá, portanto, da utilização por cada um dos sujeitos, uma dialéctica permanente entre retrospecção e prospecção, hermenêutica e heurística, que agencia a conversão de segmentos linguísticos, diversos e dispersos, mais ou menos estruturados, em textualidades vocacionadas, em termos narratológicos, para consensualidades intencionalmente procuradas. A consideração do lugar que Weil atribui às retomadas conduz, assim, à identificação de uma pragmática textual, a condicionar o agir comunicacional dos sujeitos, que replica a pragmática da linguagem em geral, pois que o seu agir nela e com ela se processa, só que num plano de maior complexidade, não só quantitativa, mas, também, qualitativamente, diferenciado, cuja coerência, sendo holística e dominada pelo valor do sentido, como princípio privilegiado de mútuo entendimento, pressupõe não só a retomada de actos de fala, determinados funcionalmente, mas, sobretudo, a retomada de esquemas narratológicos de cariz ilocutório, de textualidades orientadas pela perlocução, bem como, de segmentos textuais, buscados intertextualmente, como base locutória, que integram os primeiros segundo uma lógica específica, de tipo discursivo, a qual não saberia resultar da simples acumulação desses actos basilares. Nesta linha, cabe reconhecer, com Gilbert Kirscher, que «o discurso particular constitui um sistema singular de retomadas e podemos imaginar um número indefinido de tais sistemas».. ${ }^{15}$ Ora, se o nosso argumento estiver correcto, a aprendizagem desse modo de retomar, propriamente filosófico, está numa 
correlação estreita com a qualidade das retomadas que estão em acção nos discursos concretos.

Todo este trabalho é requerido porque, como temos vindo a estabelecer, a linguagem, na sua generalidade, sendo condição necessária, não é condição suficiente para as retomadas do sentido, carecendo, para o efeito, de uma configuração em termos discursivos. Ora, o que assim se revela é que, se a categoria se oferece como um princípio de homogeneidade ontológica relativamente ao todo da linguagem, não deixa, contudo, de indiciar uma tripla heterogeneidade: primeiro, pelo facto de a inversa não ser imediatamente verdadeira, já que, se todo o discurso é uma forma de linguagem, nem toda a linguagem é uma forma de discurso, o que força a necessidade de a linguagem ser retomada em termos discursivos; depois, por constituir uma possibilidade narratológica de textualidades com pretensão a fazerem sentido, uma de entre outras, com igual legitimidade, situação que está indiciada pela pluralidade de discursos categoriais, nenhuma esgotando em si mesma a totalidade das possibilidades possível dos sentidos possíveis, o que, se afasta o espectro da totalização, envolve a pragmática consequente na questão crítica de saber que sentido assiste à escolha de um sentido; por fim, pela sua correlação com uma atitude que, exprimindo-se em segmentos cada vez mais comuns, num determinado ponto da história, quer traduzir-se em enunciados coerentes e, assim, suscita a necessidade da convergência entre os discursos e a realidade.

Ora, a atitude, enquanto tal, apresenta o mesmo problema que detectámos na linguagem em geral: porque vai operando no entremeio de actos e de enunciados diversificados, de modo plural e heterogéneo, não consegue estabilizar o sentido desse seu enunciar permanente. Numa tal intencionalidade enunciativa, que a define progressivamente, como uma atitude, haverá, então, que identificar o que releva a expressão, pela qual a atitude se vai dizendo, o que respeita ao implícito categorial, que, só a posteriori, é verificado numa categoria que se afirma compreensiva da atitude, e o que concerne a reflexividade, pela qual toda a atitude, mais cedo ou mais tarde, quer aceder ao sentido da sua especificidade, para cá das várias atitudes e dos enunciados concretos que a compõem, isto é, à sua categoria própria. Este entendimento da relação entre atitudes e categorias torna patente um hiato, diríamos, insofismável, entre os dois termos que é, a cada etapa, preenchido pelas retomadas. Porquanto é a retomada que dá a ver quer a atitude, quer a categoria, a sua operação produz-se nos dois âmbitos, isto é, as retomadas podem ser de categorias ou de atitudes, como o próprio Weil assenta, a propósito da categoria da Certeza. ${ }^{16}$

18 As retomadas cumprem, assim, igualmente, a função de esquemas que permitem unir categorias e atitudes, na medida em que, por um lado, subsumem a diversidade das enunciações efectivas, que estão associadas a uma atitude, na unidade esquemática da discursividade categorial, enquanto, por outro, validam o sentido que esta supõe como um modo válido de existir. Este plano de conexão, quasi-discursivo, quasi-existencial, configura, como para a pragmática linguística, acima descrita, uma zona intermédia, indispensável para o entendimento da interacção entre intencionalidade e efectividade do agir discursivo. Também aqui, por um lado, não é qualquer discurso que serve para qualquer atitude, e vice-versa, enquanto, por outro, a escolha de um discurso/atitude tem consequências narratológicas e textuais que comprometem a respectiva esfera de significações, requerendo textualidades orientadas para fazer valer a combinatória de sentido e de sabedoria que o definem como visão do mundo. Ora, essas textualidades intermédias são propriamente narrativas, com alcance variado, mais discursivas, quando 
as retomadas visam a produção de um sistema filosófico, mais existenciais, quando as retomadas estão orientadas para uma versão mais ficcional, mas sempre narrativas. Essa é a razão pela qual se deverá pressupor condições narratológicas, também, para os discursos, incluindo aqueles que assumem na definição da sua textualidade própria uma pretensão a não funcionarem como narrações, sendo que uma delas é precisamente, como temos vindo a explorar, o retomar, na medida em que este se oferece como «o esquema que torna a categoria aplicável à realidade e que permite assim realizar concretamente a unidade da filosofia e da história». ${ }^{17}$

19 Torna-se, em consequência, perceptível que o retomar, sem prejuízo da matriz processual indicada, é multímodo, mas, em virtude da sua função lógico-pragmática, que a diferencia das formas correntes do uso e da apropriação subjectiva, cabe supor que essas modalidades obedeçam a uma tipologia, que admita a construção de um quadro taxionómico de «tipos ideais de retomadas, tipos que correspondem à realidade histórica, mas que não querem nem podem esgotá-la», ${ }^{18}$ e possibilite uma melhor compreensão do que se faz quando se retoma este ou aquele discurso, este ou aquele segmento textual, desta ou daquela maneira, com este ou aquele propósito. A base para esse trabalho encontra-se, parcialmente, realizada pelo próprio Weil, no fim da exposição de cada categoria, onde a exemplificação de retomadas concretas surge acompanhada por indicações sobre o tipo predominante de retomada ou na exposição da categoria formal do Sentido: directas e indirectas, ${ }^{19}$ autênticas e pseudo, ${ }^{20}$ exteriores e interiores, ${ }^{21}$ úteis, ${ }^{22}$ retomadas de retomadas, etc.. Estas variações partem de uma divisão principal, entre retomadas de justificação e retomadas de apreciação, que valida o seu carácter intencional. Como se depreende do exposto, cada uma dessas modalidades constituí uma condição narratológica de segundo grau que, como todas, carece de ser conhecida para ser devidamente praticada.

Esta passagem exigida pela narratividade, assegurada pelo retomar, decorre do que há de esquemático e de transcendental na ideação dos discursos categoriais e das atitudes vivenciais. Que se trate de uma coerência exposta na sua formalidade significa, por conseguinte, que a lógica da filosofia não consegue, por via da sua discursividade, subsumir a priori a relativa incoerência da história, anulando o hiato entre categoria e atitude. Nesta linha, queda definitivamente afastada a tentação de supor que atitudes e categorias puras, em si mesmas e na sua expressão formal, fossem figurações do absolutamente comum, por isso mesmo, suficientes para agirem sobre a realidade histórica efectiva. Ao invés, há que reconhecer a sua função predominantemente reguladora do agir discursivo, como parece decorrer da própria imagética a que Weil recorre para caracterizar as categorias, numa etapa terminal da obra - «elas não passam de protagonistas e não chegam a fazer desaparecer os outros atores nem esquecer que somente a peça inteira confere uma significação aos seus papéis» ${ }^{23}-$, de tal modo que, depois de a filosofia conseguir captá-los enquanto nexos de sensatez, na sua forma depurada e devolvê-los na versão de uma lógica categorial, isto é, de uma proposta de coerência formal da história das suas histórias, sobeja a necessidade de reinterpretar, reconfigurar e legitimar essas histórias, assim como as histórias do mundo, com as suas contradições e os seus níveis de violência, segundo a história que é tida por mais atinente à concepção de uma existência sensata. Dessa feita, a projecção de uma lógica dos sentidos possíveis constitui a proposta de um critério para orientar a decisão e a criação de sentidos comuns, não devendo confundir-se nem com uma visão substancial totalitária - a da filosofia contraposta à do mundo -, nem com uma pretensa substituição do agir 
pelo discurso. Mais, se o que a filosofia compreende como totalidade carece sempre de uma efectuação local, porquanto, como Weil assenta, «o homem fala sempre na situação sobre a situação», ${ }^{24}$ o que deve ser posto em comum é, assim, o que pode sê-lo, em determinadas circunstâncias que condicionam, igualmente, o que é possível retomar.

21 A razão é simples: a retomada constitui um operador de sentido e este resulta da reflexão discursiva sobre a espontaneidade expressiva. Nem atitude pura, portanto, nem categoria pura. Por não coincidir com nenhuma das duas figuras, o seu procedimento básico consiste, segundo Weil, em recuperar uma atitude/categoria anterior para viabilizar o acesso ao sentido da actual, dando, em consequência, origem a uma quantidade de discursos explicativos, justificativos, valorativos, etc.. que cumprem, globalmente, uma dupla função, conversiva e educativa. ${ }^{25}$ Uma nova atitude/categoria vai-se assim construindo pelo recurso a atitudes e categorias prévias que são retomadas como nexos de significação já estabelecidos, confirmados, validados e, logo, disponíveis para traduzir o que devém como alteridade e novidade na história. Só que, como o filósofo esclarece, não é a atitude/categoria anterior que constituirá a necessidade da nova, o que reduziria a inventividade do sentido a um procedimento determinístico, mas o inverso, «isso porque a passagem de uma categoria a outra não se compreende do ponto de vista da primeira, e só aparece como necessária após o aparecimento da nova categoria, necessária com a necessidade que esta cria livremente». ${ }^{26} \mathrm{~A}$ característica paradoxal do retomar, que assim é acentuada, a do anacronia do seu proceder, define como condição de possibilidade da produção de sentido, em geral, logo, do que pode ser posto em comum, que toda a inovação careça de retroacção, por via de retomadas, o que reforça a legitimidade da nossa hipótese sobre a existência de uma proporcionalidade directa entre o conhecimento dos esquemas textuais que temos vindo a destacar e a eficácia da produção de novos segmentos, em particular quando estes se afiguram não-ficcionais e visam operar alterações significativas na cultura ambiente. Todavia, o que fica, igualmente, à vista é o peso dessa cultura quer no que é retomado, quer no processo de retomar.

Assim, se, pela retomada, se limita a pletora da espontaneidade expressiva, posto que, ao retomar-se, já se visa um princípio de ordenação narratológica e, nessa medida, se condiciona o que se procura impor ideologicamente, uma inovação pura ou a criatividade inaugural, não deixa de ser, igualmente, manifesto que a retomada é o processo da liberdade em acto, numa situação concreta, para cá e para lá dessa determinação, uma vez que traduz o que há de transcendente no intento de transmutar a violência no sentido, por via da busca poética de novos sentidos, com e para os sentidos presentes. Nesta medida, ao conjugar os dois significados de condição - delimitação e viabilização -, na concretude da história, o dinamismo da retomada destaca-se da relativa imobilidade das arquitextualidades categoriais, por nos lançar na voragem dos discursos comuns em busca de um nível de comunidade mais estreito, melhor orientado, porque tido por mais sensato, mais livre, mesmo quando acaba por não ser esse o resultado ou por mais raro que este se afigure. A retomada, por conseguinte, decorre de e inscreve o princípio do comum no seio das diferenças discursivas, não para as reduzir ou resolver uma solução única, mas para garantir a conjugação entre uma coerência projectada e uma variabilidade desejada. Por isso, como defendeu Kirscher, valorizando, outrossim, a sua dimensão hermenêutica, cabe distingui-la da ideologia, ${ }^{27}$ entendida como um exercício de suspeita sobre o saber dos outros, baseado na auto-afirmação de uma ciência assumida na forma da certeza. Pelo contrário, em virtude da detecção do seu carácter universal, 
oferece-se como uma constante antropológica animada pelo intuito de gerar formas do comum, seja como resposta à limitação temporal que a define, lidando com o hiato entre sentidos disponíveis e sentidos em elaboração. No acto de retomar, a dimensão crítica está implicada na intencionalidade constitutiva, de modo que a aceitação ou a recusa de uma determinada sequência é correlata desse vector. Ainda que certas retomadas visem repor a hegemonia de uma categoria/atitude, esse propósito só confirma que, por via do retomar, a tendência para que uma categoria/atitude valha como ideologia dominante acaba enfraquecida.

Este efeito difractivo do retomar suscita, por sua vez, a reflexão sobre o problema da existência de uma proporção directa entre a quantidade de discursos que patenteiam a sua dependência estrutural do dispositivo da retomada, num regime de inautenticidade, mais ou menos explicitada, cultivando a mera combinação de retomadas consagradas, e a situação histórica que usualmente se compreende como crise. Mantendo-nos no nosso âmbito reflexivo, diríamos que essa utilização da ossatura performativa, enquanto mero formalismo, decorre tanto da perda de evidência de uma atitude como de coerência de uma categoria capaz de centralizar a pluralidade de sentidos em circulação e, por essa via, de compensar o que há de repetitivo e de anacrónico na retomada. Quando predomina uma constelação de atitude/categoria, esse aspecto desgastante e desgastado do uso comum da linguagem é compensado pela referência ao sentido da existência e do discurso: é como se falar do mesmo estivesse justificado a priori pela sacralidade do mesmo de que se fala. Ao invés, a crise desse padrão releva o que há de esquemático nesse comum, ou seja, um tipo de funcionamento que se esgota em retomadas de retomadas. Nestas circunstâncias, a retomada aproxima-se perigosamente da «reprehensio» retórica, ${ }^{28}$ ficando, progressivamente, obscurecido o seu papel prospectivo, na base da inovação cultural.

Um dos significados de crise das narrativas consistirá, por conseguinte, numa alteração da posição relativa dos três termos - atitude, categoria, retomada - fazendo com que a retomada passe de mediadora a protagonista, de esquema a procedimento hegemónico, funcionando, assim, em roda livre. Este estado de coisas caracteriza, precisamente, a nossa época, que, a si mesma, se oferece e se reconhece como uma época de crise. Ora, se a tentação é grande de confundir esta predominância lógica da retomada como a causa ou o efeito da crise, impõe-se ter presente que a retomada é o mecanismo discursivo que não só garante uma certa continuidade paradigmática, como está na origem das percepções da crise enquanto tal, pelo que, sem a mediação do retomar, a crise seria mera negação do paradigma anterior. Mais, as críticas que são produzidas contra a crise da crise redundam em retomadas de atitudes/categorias anteriores que são convocadas para exemplificarem figuras de estabilidade e de orientação.

Fica, deste modo, patente uma diferença importante, não pensada por Weil, entre o acto e o produto, isto é, entre o retomar e as retomadas. Na verdade, esta diferença emerge do duplo carácter lógico e pragmático, discursivo e performativo, que detectámos na retomada. A escolha da forma verbal no nosso título advém da tomada de consciência deste diferencial e, sobretudo, do modo como ele deve afectar a formulação da dialéctica entre transcendentalidade e historicidade que lhe é inerente: se retomar é preciso, e as retomadas surgem com o carácter de necessidade, nem todas as retomas estão ipso facto legitimadas. Assim, se na compreensão da história importa reconhecer a série das retomadas, tal como se deram, já no que respeita à prática actual do retomar, um trabalho de outra ordem tem de ser efectuado com vista a decidir não só o que importa retomar, 
mas também se a forma das retomadas não encerra o discurso numa espécie de funcionamento anómalo, segundo o qual as retomadas se tornam sistémicas, cristalizando-se num tique repetitivo e perdendo a referência ao sentido. É que retomar, como tentámos mostrar, não é uma opção, mas uma condição performativa, ao contrário das retomadas que podem e devem ser escolhidas. Será, então, de ponderar, como Paul Ricoeur defendia relativamente às metáforas, a existência de retomadas mortas e de retomadas vivas, coexistindo, em proporções variáveis, em configurações culturais diferenciadas.

Todavia, importa não ver nesta oposição uma solução explicativa simples para a crise, por se assumir que esta mais não seria do que a expressão da morte das retomadas que previamente estavam em perfeito funcionamento. Se aplicarmos as considerações que fomos tecendo, o excedente de retomadas é sinal claro de uma crise narratológica coeva, mas não menos do esforço para superá-la. Esta situação decorre da pragmática do retomar que persiste nas retomadas, sem dúvida, mas, não menos significativamente, no próprio retomar. Aliás, a ilusão quietista de que partilhamos cada vez mais um mesmo horizonte de sentido, de acordo com o processo de globalização, que vale pelo comunitarismo perdido, é produzida, em grande parte, como efeito da prevalência do retomar, na forma mecânica do repetir improcedente, sobre outros dispositivos narratológicos, razão pela qual surge acompanhada pela consciência de um esgotamento da dimensão poiética que caracteriza toda a versão original, isto é, destinada tanto a dar, quanto a fazer, sentido aos sentidos disponíveis e pela consequente expectativa de um desfecho alternativo.

O que fica por decidir, já que não se nos afigura ainda decidido, é o estatuto deste trânsito: cada vez mais discutimos conscientemente por via de retomadas, criticamos em nome de retomadas, argumentamos retomando, exprimimo-nos, mesmo nos domínios da criação artística e literária, ao retomar formas e figuras anteriores, sabendo-as cristalizadas, que assim se confundem com citações mais ou menos literais, como consequência de estarmos centrados na categoria/atitude da Acção, a qual depende das retomadas para fazer valer o sentido do seu projecto revolucionário, «visto que o universal não está realizado», ${ }^{29}$ junto do «indivíduo [que] pede para ser aquele que justamente compreende e para deixar de ser aquele que é compreendido», ${ }^{30}$ como Weil pretendia ou por esgotamento do sentido da mesma, traduzido numa recuperação da Obra, "violência presente» ${ }^{31}$ do «criar para criar», ${ }^{32}$ em cujo discurso "não se distinguem com segurança absoluta as retomadas verdadeiras das pseudorretomadas, porque estas se dedicarão precisamente a imitar aquelas o melhor possível», ${ }^{33}$ pois que «ao falar todas as línguas, ela sabe que nenhuma delas tem sentido para ela», ${ }^{34}$ ou por já estarmos no limiar de uma nova categoria/atitude, destinada a funcionar como centro gerador de outras retomadas? o que, em contrapartida, esperamos ter conseguido mostrar, é que, se «a regra é o que foi por nós denominado a retomada», ${ }^{35}$ qualquer tentativa de resposta não poderá deixar de ponderar a centralidade dos processos de retomar. 


\section{NOTAS}

1. A heterodoxia da mise en abyme assim praticada supõe a ortodoxia de outras interpretações, como aquelas que se encontram neste volume ou, noutros, como, por exemplo: G. Kirscher, La philosophie d'Eric Weil, Paris, PUF, 1989; P. CANIVEZ, Weil, Paris, Les Belles Lettres, 1999; F. Guibal, Le sens de la réalité, Paris, Éditions du félin, 2011.

2. Eric Weil, Lógica da Filosofia, São Paulo, É Realizações, 2012, p. 123. Neste ensaio, conformamonos ao uso do termo retomada, como tradução de reprise, por ter sido aquele adoptado quer pelos weilianos do Brasil, quer por esta importante versão, de acordo com as razões indicadas por Marcelo Perine no seu contributo, ainda que continuemos convictos de que «reassunção», que sempre privilegiámos, melhor distinga o processo em causa de outros congéneres no campo da hermenêutica filosófica e, dessa feita, não se preste, com a mesma facilidade, a aproximações equívocas.
3. Ibidem, p. 145.
4. Ibidem, p. 144.
5. Ibidem, p. 608.
6. Ibidem, p. $594-595$.
7. Ibidem, p. 606.
8. Ibidem, p. 593.
9. Ibidem, p. 598.
10. Ibidem, p. 578.

11. L. Bernardo, Linguagem e Discurso: uma hipótese hermenêutica sobre a filosofia de Eric Weil, Lisboa, Imprensa Nacional-Casa da Moeda, 2003.

12. I. Kant, $\mathrm{KrV}$, A137/B176.

13. Eric Weil, Lógica da Filosofia, p. 105.

14. Ibidem, p. 173.

15. Gilbert Kirscher, Figures de la violence et de la modernité, Lille, PUL, 1992, p. 47.

16. Eric Weil, Lógica da Filosofia, p. 173.

17. Ibidem, p. 123.

18. Ibidem, p. 248.

19. Ibidem, p. 174.

20. Ibidem, p. 516-517.

21. Ibidem, p. 571.

22. Ibidem, p. 585.

23. Ibidem, p. 605.

24. Ibidem, p. 600 .

25. Ibidem, p. 604.

26. Ibidem, p. 248.

27. Gilbert Kirscher, Figures de la violence et de la modernité, Lille, PUL, 1992, p. 47.

28. C. Perelman/L. Olbrechts-Tyteca, Traité de l'argumentation, Bruxelas, Édition de l'Université de Bruxelles, 2008, p. 235.

29. Eric Weil, Lógica da Filosofia, p. 571.

30. Ibidem, p. 569.

31. Ibidem, p. 515.

32. Ibidem, p. 497.

33. Ibidem, p. 517. 


\section{RESUMOS}

O que é posto em comum depende, em grande parte, de processos textuais específi cos que funcionam como condições de possibilidade pragmático-narratológicas da partilha dos sentidos que circulam pelo meio da linguagem. Tal implica que o simples uso corrente da linguagem, ao contrário do que é usual supor, ainda que indispensável, não seja sufi ciente para gerar essa comunidade, pois que nem todos os dispositivos linguísticos estão vocacionados para favorecer a convergência. Neste artigo, pretendemos, por conseguinte, reflectir sobre uma dessas condições, a de que uma nova enunciação, para se tornar comum, tenha sempre de retomar uma versão enunciativa, já consolidada, não apenas formalmente, mas, também, no que respeita a sequências textuais específicas. Para o efeito, estendemos o conceito de retomada que, na filosofia de Eric Weil, surge no âmbito da Lógica da Filosofia, à totalidade da comunicação com pretensão a fazer sentido. Trata-se, portanto, de pensar com Weil, para lá de Weil, num exercício de (in)fidelidade e distanciação que constitui, em si mesmo, uma forma de o retomar.

Ce qui est mis en commun dépend, en grande partie, de procédés textuels spécifiques qui fonctionnent en tant que conditions de possibilité pragmatiques et narratologiques du partage des significations qui circulent dans le médium du langage. Contrairement aux versions dominantes, il apparait donc que l'utilisation courante du langage, en général, c'est-à-dire non orientée vers la production de discours, bien qu'indispensable, ne s'avère pas suffisante pour générer cette communauté, n'ayant pas pour but conséquent une telle convergence. C'est ainsi qu'avec cet article nous voulons réfléchir sur une de ces conditions, celle qui oblige toute nouvelle énonciation voulant se rendre commune à reprendre une version énonciative déjà bien établie, non seulement en ce qui concerne la forme, mais aussi en ce qui relève de séquences textuelles précises. Pour le faire, nous transposons le concept weilien de reprise de la Logique de la philosophie à l'ensemble de la communication sensée. Il s'agit, ainsi, de penser avec Weil au-delà de Weil, en proposant un exercice d'(in)fidélité et de mise à distance qui, en fait, revient à une façon de le reprendre.

\section{ÍNDICE}

Palavras-chave: sentido, retomada, linguagem, discurso, textualidade

Mots-clés: sens, reprise, langage, discours, textualité

\section{AUTOR}

\section{LUÍS MANUEL A. V. BERNARDO}

CHC / Departamento de Filosofia / FCSH / Universidade Nova de Lisboa Professor do Departamento de Filosofia da FCSH da UNL; Subdirector do Centro de História da Cultura da mesma instituição. Realizou as suas dissertações de mestrado e de doutoramento em 
torno da filosofia de Eric Weil sobre a qual tem publicado com regularidade, nomeadamente: Linguagem e Discurso: Uma Hipótese Hermenêutica sobre a Filosofia de Eric Weil, Lisboa, Imprensa Nacional-Casa da Moeda, 2003 (394 págs.); “Uma Lógica da Filosofia da Educação? Considerações à Volta de uma Ideia", Anais do IV Colóquio Franco-Brasileiro de Filosofia da Educação - Filosofia, Aprendizagem, Experiência, Rio de Janeiro, Universidade Estadual do Rio de Janeiro, 2008, pp. 1-22; "Reasons of Violence, Violence of Reason: an Interpretation based on Eric Weil's Core Paradox", Diogo Pires Aurélio/João Tiago Proença (ed.), Terrorism: Politics, Religion, Literature, Newcastle upon Tyne, Cambridge Scholars Publishing, 2011, pp. 35-67; “Moral, Educação e Sentido: uma leitura da Filosofia Moral de Eric Weil”, Revista Itinerarium, Ano LVII, no 199, Janeiro-Abril 2011, pp. 3-40; “A Discussão entre Política e Educação: à volta de Eric Weil e de Jürgen Habermas", Michel Renaud/Gonçalo Marcelo (coord.), Ética, Crise e Sociedade, Lisboa, Húmus/CHC, 2011, pp. 267-299.

Professeur du Département de Philosophie de la FCSH-UNL; sous-directeur du Centre d'histoire de la culture de la même institution. Maitrise et doctorat dédiés à la philosophie d'Eric Weil sur laquelle il publie régulièrement, notamment : Linguagem e Discurso: Uma Hipótese Hermenêutica sobre a Filosofia de Eric Weil, Lisboa, Imprensa Nacional-Casa da Moeda, 2003 (394 págs.); “Uma Lógica da Filosofia da Educação? Considerações à Volta de uma Ideia”, Anais do IV Colóquio FrancoBrasileiro de Filosofia da Educação - Filosofia, Aprendizagem, Experiência, Rio de Janeiro, Universidade Estadual do Rio de Janeiro, 2008, pp. 1-22; "Reasons of Violence, Violence of Reason: an Interpretation based on Eric Weil's Core Paradox”, Diogo Pires Aurélio/João Tiago Proença (ed.), Terrorism: Politics, Religion, Literature, Newcastle upon Tyne, Cambridge Scholars Publishing, 2011, pp. 35-67; “Moral, Educação e Sentido: uma leitura da Filosofia Moral de Eric Weil", Revista Itinerarium, Ano LVII, no 199, Janeiro-Abril 2011, pp. 3-40; “A Discussão entre Política e Educação: à volta de Eric Weil e de Jürgen Habermas", Michel Renaud/Gonçalo Marcelo (coord.), Ética, Crise e Sociedade, Lisboa, Húmus/CHC, 2011, pp. 267-299. 